Sharif University of Technology
Scientia Iranica
SCIENTIA
I RAN I CA

\title{
Application of trend analysis and artificial neural networks methods: The case of Sakarya River
}

\author{
G. Ceribasi ${ }^{\mathrm{a}, *}$, E. $\operatorname{Dogan}^{\mathrm{b}}$, U. Akkaya ${ }^{\mathrm{c}}$ and U.E. Kocamaz ${ }^{\mathrm{d}}$ \\ a. Sakarya University, Technology Faculty, Department of Civil Engineering, Sakarya, Turkey. \\ b. Sakarya University, Faculty of Engineering, Department of Civil Engineering, Sakarya, Turkey. \\ c. Sakarya University, Science Institute, Department of Civil Engineering, Bolu, Turkey. \\ d. Uludag University, Vocational School of Karacabey, Department of Computer Technology, Bursa, Turkey. \\ Received 7 November 2015; received in revised form 1 February 2016; accepted 5 September 2016
}

\section{KEYWORDS}

Trend analysis; Artificial neural networks;

Sakarya river;

Rainfall;

Stream flow;

Suspended load.

\begin{abstract}
Various artificial intelligence techniques are used in order to make prospective estimations with available data. The most common and applied method among these artificial intelligence techniques is Artificial Neural Networks (ANN). On the other hand, another method which is used in order to make prospective estimations with available data is Trend Analysis. When the relation of these two methods is analyzed, Artificial Neural Networks method can present the prospective estimation numerically, while there is no such a case in Trend Analysis. Trend Analysis method presents result of prospective estimation as a decrease or increase in data. Therefore, it is quite important to make a comparison between these methods which brings about prospective estimation with the available data, because these two methods are used in most of these studies. In this study, annual average stream flow and suspended load measured in Sakarya River along with average annual rainfall trend were analyzed with trend analysis method. Daily, weekly, and monthly average stream flows and suspended loads measured in Sakarya River and average daily, weekly, and monthly rainfall data of Sakarya were all analyzed by ANN Model. Results of trend analysis method and ANN model were compared.
\end{abstract}

(C) 2017 Sharif University of Technology. All rights reserved.

\section{Introduction}

Due to recent climate changes, hydraulic structures are being built in order to effectively use water resources, which are in danger of being consumed totally. Some important parameters are estimated properly in order to complete economic life of hydraulic structures in the planned time schedule. The most important parameter is the amount of solid material carried by the river throughout the planned life of the structure [1]. There-

*. Corresponding author. Tel.: +902642956510;

Fax: +902642956424

E-mail addresses: gceribasi@sakarya.edu.tr (G. Ceribasi); emrahd@sakarya.edu.tr(E.Dogan); ugurakkaya@ibu.edu.tr (U. Akkaya); ugurkocamaz@gmail.com (U. Erkin Kocamaz) fore, this study aims to make a prospective estimation of suspended load transported by the river.

In recent years, Artificial Neural Networks (ANN) have been used in various disciplines effectively and commonly since they can form an easy, fast and more accurate model with low error margin on the basis of nonlinear relations among parameters which influence cases [1].

On the other hand, since hydrological sizes (rainfall, stream flow, suspended load, etc.) have a randomly changing characteristic in time, special methods are required to analyze a continuous decrease or increase trend [2-6]. Basic assumptions, such as normality, linearity, and independence, about classical parametric tests are not practicalized yet in typical surface water quality. Therefore, it is suitable to use non- 
parametric tests rather than parametric ones. These non-parametric tests are: Mann-Kendall, Spearman's Rho, and Mann-Kendall Rank-Correlations tests. The method which includes all these tests is Trend Analysis method [4-6].

It is quite important to make a comparison between these methods since both of them make prospective estimation with available data due to the fact that these two methods are being used in most of the studies that have been carried out in recent years. Therefore, it is one of the most important issues to analyze whether these two methods contradict or correspond to each other. Therefore, this study aims to apply Trend Analysis Method and Artificial Neural Networks Method to rainfall, stream flow, and suspended load of Sakarya river and Sakarya city.

\section{Materials and methods}

In order to apply Artificial Neural Networks Method, this paper considered daily, weekly, and monthly average stream flows and suspended loads of Stream Flow Observation Station no. 1257 of Sakarya River as well as daily, weekly, and monthly average rainfall of State Meteorological Station no. 17069 of Sakarya city $[7,8]$. In order to apply trend analysis method, annual average stream flow and suspended load of Stream Flow Observation Station no. 1257 of Sakarya city and annual average rainfall of State Meteorological station no. 17069 of Sakarya city were used.

\subsection{Artificial neural networks method}

MATLAB program was used while implementing Artificial Neural Networks Method. ANN method was applied as three years of training, one year of validation, and one year of testing. Data of daily stream flow, suspended load and rainfall of 33 years in total (19792011) were used which constituted $65 \%$ training, $18 \%$ validation, and $17 \%$ test, respectively.

One of the issues deserving attention in ANN studies is the determination of number and characteristics of input. Determination of suitable input can be effective in problem-solving [9-13]. In this study, various tests were made in order to determine correct input parameters. As a result of these tests, ANN model composed of 4 inputs and 1 output was determined.

In ANN model: Day no, Water year, Rainfall $(\mathrm{mm})$, and Stream flow $\left(\mathrm{m}^{3} / \mathrm{s}\right)$, were used as inputs, and the suspended load values (ton/day) were used as output.

\subsection{Trend analysis method}

\subsubsection{Spearman's Rho test}

This is a quick and simple test to determine if there is a correlation between two observation series. $R_{x i}$, i.e. rank statistic, was determined by ordering data in increasing or decreasing order. Spearman's Rho test statistics $\left(r_{s}\right)$ was calculated according to the following equation $[3,14]$ :

$$
r_{s}=1-6 \frac{\sum_{i=1}^{n}\left(R_{x i}-i\right)^{2}}{\left(n^{3}-n\right)} .
$$

Since $r_{s}$ distribution was close to normal for $n>30$, normal distribution tables were used. So, test statistics $(Z)$ of $r_{s}$ is as follows:

$$
Z=r_{s} \sqrt{n-1} \text {. }
$$

It is concluded that if normal distribution corresponding to $\alpha$ significance level, which is chosen as absolute value of $Z$, is smaller than $Z_{\alpha / 2}$, then null hypothesis is accepted. In addition, there is no trend in time series observed if it is bigger. Consequently, there is a trend, and if $Z$ value is positive, then there is an increase trend; if it is negative, then there is a decrease trend.

\subsubsection{Mann-Kendall test}

Since the Mann-Kendall test is a non-parametric test, it is independent from random variable distribution. With this test, the presence of a trend in a time series is checked with null hypothesis " $H_{0}$ : no trend" [15-20]. In $x_{1}, x_{2}, \ldots, x_{n}$ time series to which the test will be applied, $x_{i}, x_{j}$ pairs are divided into two groups. For $i<j$, if $P$ represents the number of pairs $x_{i}<x_{j}$ and number of pairs $x_{i}>x_{j}$, test statistics $(S)$ is calculated by the following relation:

$$
S=P-M
$$

Kendall correlation coefficient is calculated as follows:

$$
\tau=\frac{S}{[n(n-1) / 2]} .
$$

For $n \geq 10$ :

$$
\begin{gathered}
\sigma_{s}=\sqrt{n(n-1)(2 n+5) / 18}, \\
Z= \begin{cases}(S-1) / \sigma_{s} & S>0 \\
0 & S=0 \\
(S+1) / \sigma_{s} & S<0\end{cases}
\end{gathered}
$$

It is concluded that if normal distribution corresponding to $\alpha$ significance level, chosen as the absolute value of $Z$, is smaller than $Z_{\alpha / 2}$, then null hypothesis is accepted. Moreover, there is no trend in time series observed if it is bigger; there is a trend and if $Z$ value is positive, then there is an increase trend; if it is negative, then there is a decrease trend [4-6,21-24].

\subsubsection{Mann-Kendall rank correlation test}

This nonparametric test is used to determine whether an increase or decrease trend is present in the applied series in time. The test graphically expresses the results and also determines starting point of the trend [3-5]. In 


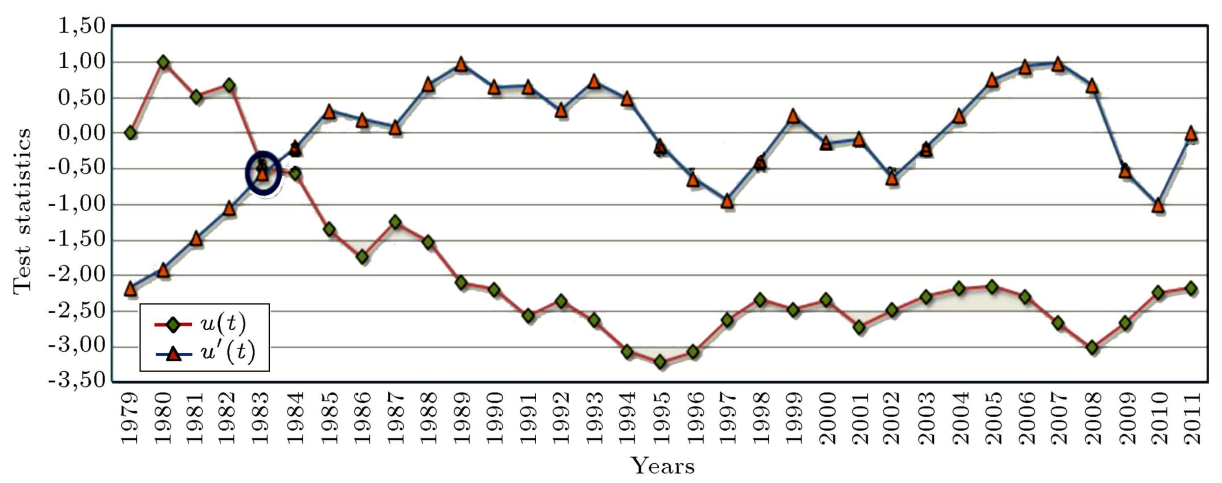

Figure 1. $u(t)-u^{\prime}(t)$ graph of the annual flow of Sakarya River.

the hydro-meteorology time series, starting from the left-hand side, the data $x_{i}$ are considered to be the larger ones in the data that comes before itself instead of the data. If this number is called $n_{i}$, then $x_{i}$ data values are replaced with them and a whole number sample function is obtained. If $t_{i}$ represents sequential sums of these whole numbers, $t$, which is required by the magnitude to test the method, becomes:

$$
t=\sum_{i=1}^{n} n_{i} .
$$

Mean $E(t)$ follows:

$$
E(t)=\frac{n(n-1)}{4}
$$

variance follows:

$$
\operatorname{var}(t)=\frac{n(n-1)(2 n+5)}{72} .
$$

and $u(t)$ function follows:

$$
u(t)=\frac{[t-E(t)]}{\sqrt{\operatorname{var}(t)}} .
$$

Considering the assumption that there is no change over time expressed by the near-zero values of $u(t)$, the bigger values of $u(t)$, surprisingly, show that a change occurs. On the other hand, graphical intersection point of $u(t)$ and $u^{\prime}(t)$ shows the starting time of the trend.

\section{Results and discussion}

\subsection{Results of the trend analysis method}

Results of Spearman's Rho and Mann-Kendall tests of the stream flow, suspended load, and rainfall data of Sakarya River and Sakarya are given in Table 1.
When Trend Analysis results were analyzed, it was seen that there is a decrease trend in stream flow, suspended load, and rainfall for both tests (Spearman's Rho and Mann-Kendall tests).

Graphic results of Mann-Kendall Rank Correlation test of the stream flow and suspended load data of Sakarya River and rainfall data of Sakarya are given in Figures 1, 2 and 3.

According to Mann-Kendall rank correlation test, the starting years of a decrease trends are the year 1983 for stream flow, 1983 for suspended load, and 1985 for rainfall. Therefore, these results were obtained when accuracy of the results of trend analysis was analyzed.

\subsection{Results of artificial neural networks method}

ANN model was applied as three years of training, one year of validation, and one year of testing. $65 \%$ of the whole 33 years of data was for training, $18 \%$ for validation, and $17 \%$ for testing. Daily testing performance, weekly testing performance, and monthly testing performance are given in In Figures 4, 5 and 6, respectively.

When graphics of Figures 4-6 are analyzed, the best test performance is the graph of test performance of suspended load predicted by ANN with the aid of average daily data. But, in order to be certain of this, the decision can be made after analyzing validation performances. On the other hand, results of daily, weekly, and monthly test scatter of real values and predicted values are given in Figure 7 .

$R^{2}$ is close to the value of 1 as given in Figure 7 , and so, we can discuss such a successful ANN. Moreover, if an ANN model is trained with much data,

Table 1. Results of Spearman's Rho and Mann-Kendall tests of the stream flow, suspended load, and rainfall data.

\begin{tabular}{lcccc}
\hline \multirow{2}{*}{ The station } & $\begin{array}{c}\text { Spearman's Rho test } \\
\left(\boldsymbol{r}_{\boldsymbol{s}}\right)\end{array}$ & $\begin{array}{c}\text { Spearman's Rho } \\
\text { test }(\mathbf{Z})\end{array}$ & $\begin{array}{c}\text { Mann-Kendall } \\
\text { test }(\boldsymbol{\tau})\end{array}$ & $\begin{array}{c}\text { Mann-Kendall } \\
\text { test }(\mathbf{Z})\end{array}$ \\
\hline Stream flow $\left(\mathrm{m}^{3} / \mathrm{s}\right)$ & $-0,39$ & $\mathbf{- 2 , 1 8}$ & $-0,27$ & $\mathbf{- 2 , 1 5}$ \\
Suspended load (tons/day) & $-0,50$ & $\mathbf{- 2 , 8 3}$ & $-0,36$ & $\mathbf{- 2 , 9 6}$ \\
Rainfall $(\mathrm{mm})$ & $-0,55$ & $\mathbf{- 3 , 1 5}$ & $-0,40$ & $\mathbf{- 3 , 2 9}$ \\
\hline
\end{tabular}




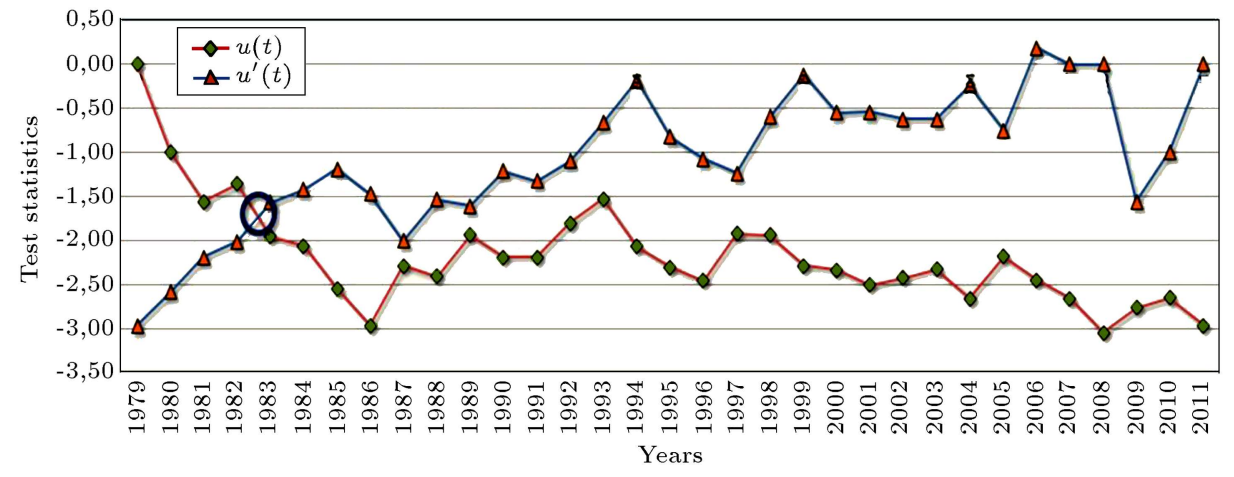

Figure 2. $u(t)-u^{\prime}(t)$ graph of the annual suspended load of Sakarya River.

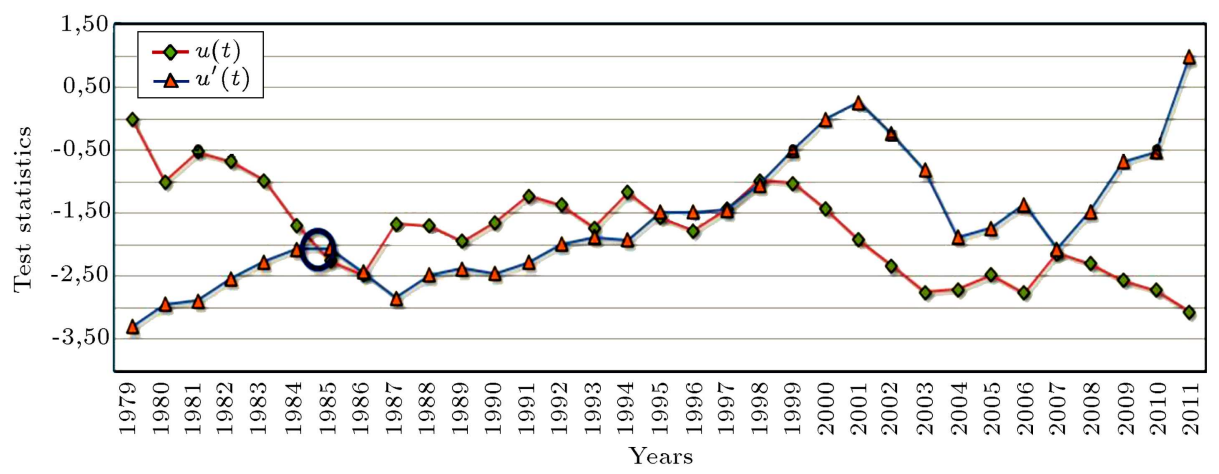

Figure 3. $u(t)-u^{\prime}(t)$ graph of the annual rainfall of Sakarya.

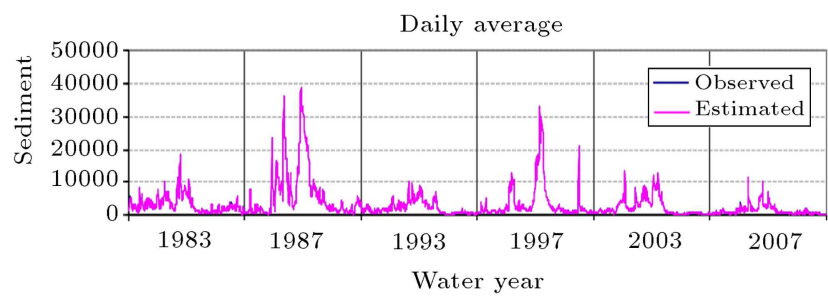

Figure 4. Test performances of predicting suspended load levels with ANNs using average daily data.

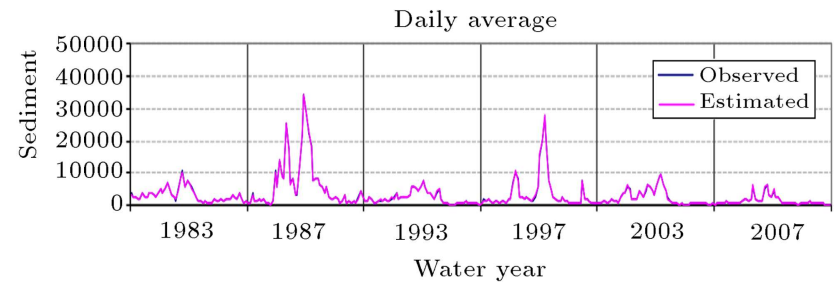

Figure 5. Test performances of predicting suspended load levels with ANNs using average weekly data.

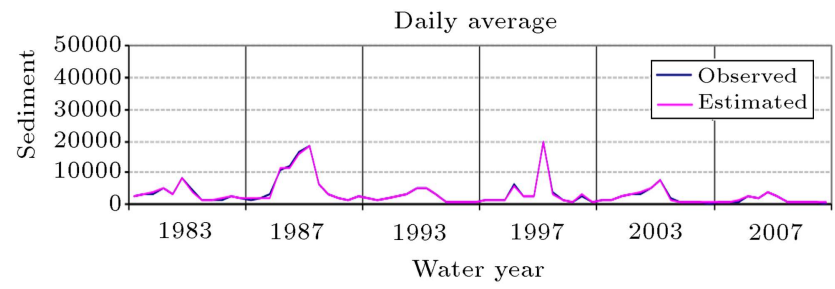

Figure 6. Test performances of predicting suspended load levels with ANNs using average monthly data. a much more successful ANN model will be formed. Therefore, when the graphics in Figure 7 are observed, the value of daily test determination coefficient is the closest to that of $R^{2}$. The reason is that while 365 data are used in daily data, 52 data are used in weekly data and 12 data in annual data. Again, validation performance should be considered in order to make a decision on daily data.

Real average stream flow and real average rainfall values were used while calculating validation performances. When Figures 8 to 10 are analyzed, it is seen that the best test performance is the graphs of validation performance of suspended load predicted by ANN with the aid of average daily data. On the other hand, results of daily, weekly, and monthly test scatter of real and predicted values are given in Figure 11.

When the graphics in Figure 11 are analyzed, daily validation determination coefficient value is the closest to $R^{2}$ value.

Afterwards, graphics of validation performances of suspended load with ANN are analyzed by using average monthly values in Figures 8 to 10 . Graphics of average daily, weekly, and monthly validation correlations of real and predicted values are presented in Figure 11. It is seen that the best validation performance is the validation performance of average daily data. Therefore, the best test performance is the performance of average daily data.

According to these statistics, prospective (be- 


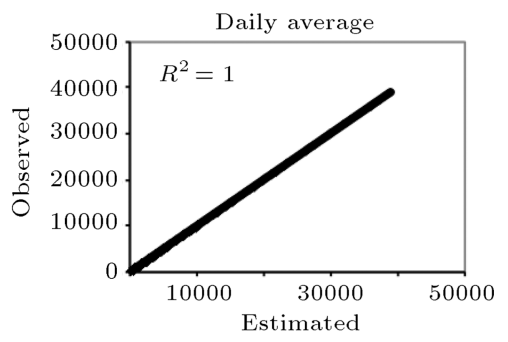

(a)

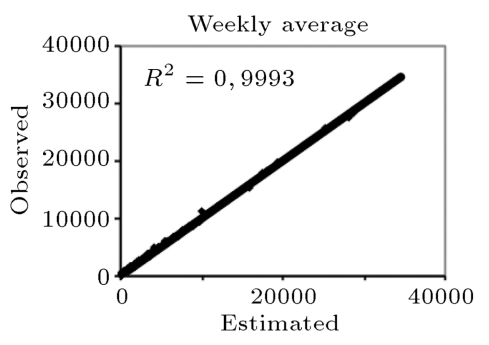

(b)

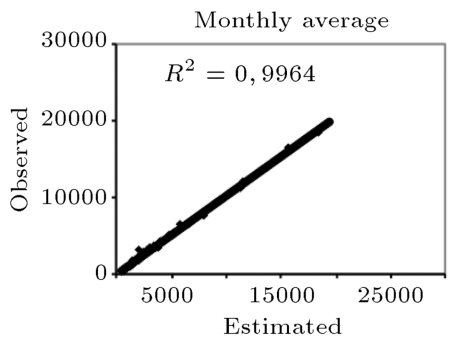

(c)

Figure 7. Comparison between observed and daily (a), weekly (b), monthly (c) simulated sediment level with ANNs for test data.

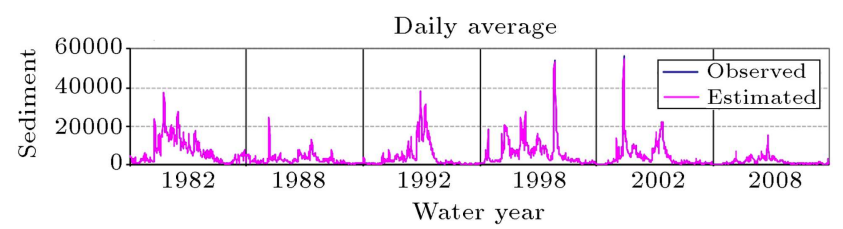

Figure 8. Validation performances of predicting suspended load levels with ANNs using average daily data.

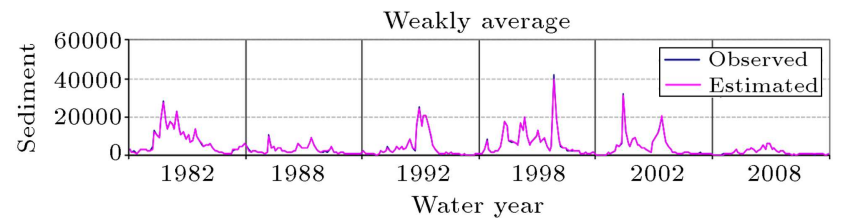

Figure 9. Validation performances of predicting suspended load levels with ANNs using average weekly data.

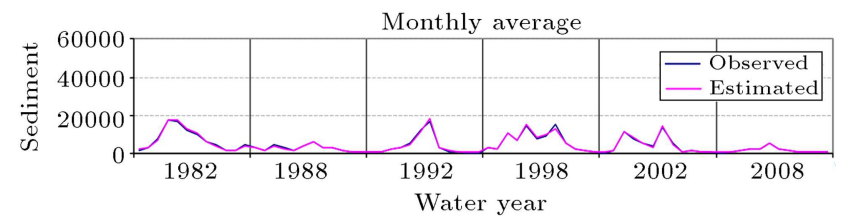

Figure 10. Validation performances of predicting suspended load levels with ANNs using average monthly data.

tween 2012-2023) suspended load prediction of ANN method was done, trained with average daily rainfall, stream flow, and suspended load data (Figure 12).

Sakarya River suspended load, which was predicted by ANN model, has a decrease trend compared to every passing year.

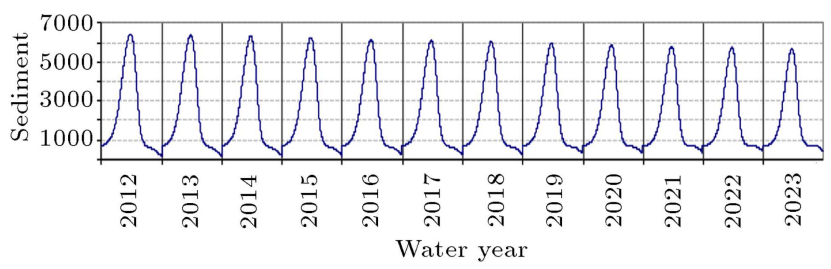

Figure 12. Forecasting suspended load levels with ANNs using daily data.

\section{Conclusion}

The factors causing decrease for hydraulic parameters were analyzed. When the year 1972 is considered which is the time Gökçekaya Dam on Sakarya River began storing water with storage volume of $910 \times 106 \mathrm{~m}^{3}$, it is seen that the starting point of trends starts after this time. Therefore, since Gökçekaya Dam arranged stream flows respectively and kept suspended load in dead storage, it caused decrease both in stream flow and suspended load. Moreover, when starting and completion dates of Sarıar Dam building in the region are considered and when the year 1956, which is the completion date of Sarıyar Dam building, is regarded as the year it began to store water, Sariyar Dam can be seen as a factor in the decrease of stream flow and suspended load [4,25-28].

With respect to climate, considering that water resources can be affected by global warming, it is estimated that water resources in specific regions of the world will run out and be insufficient in 50 years. As a result of this influence, it is estimated that the amount of water per people would be nearly $40 \%$ in

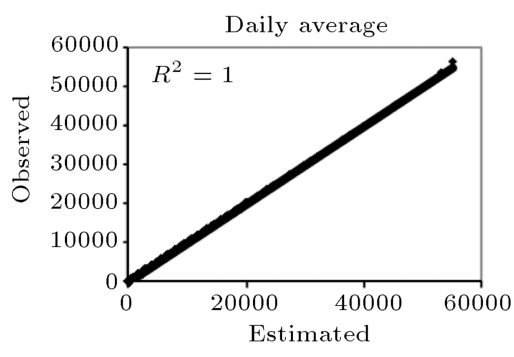

(a)

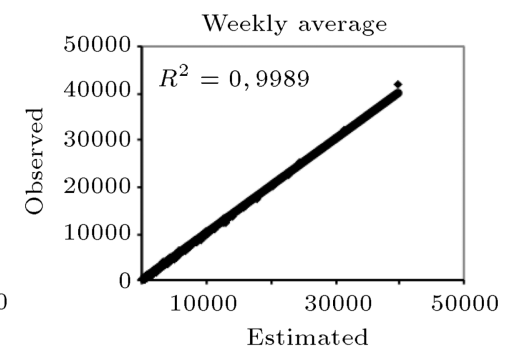

(b)

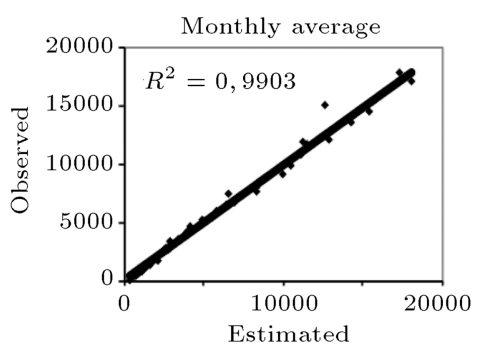

(c)

Figure 11. Comparison between observed and daily (a), weekly (b), monthly (c) simulated sediment level with ANNs for validation data. 
Turkey, which is a high value. Since Turkey is in semi-arid climate zone, it is clear that climate change would surely be influential. As it is understood from these results, it is seen that results of Trend Analysis correspond to the study that was carried out.

On the other hand, according to the results of test analyses obtained after daily, weekly, and monthly training analyses, it is seen that the best result is obtained at daily test results. As a result of validation test analysis carried out in order to assure the accuracy of test analysis result, it was again observed that daily validation test results present the best results. Therefore, Artificial Neural Networks, trained in this way, would give more accurate results for the future predictions to be carried out for Sakarya River suspended load. As a result of ANN method applied in this way, it is observed in Figure 12 as well that the suspended load predicted between 2012-2023 continues by decreasing every year. In other words, based on Artificial Neural Network method, it is observed that there is a decrease trend in suspended load transported by Sakarya River.

Therefore, it is observed that trend analysis and artificial neural network methods applied to the suspended load data of Sakarya River correspond, which means that the results of both methods are similar in the comparison.

\section{References}

1. Kayaalp, N. "Determination of monthly suspendedsediment load transported in dicle river with artificial neural networks", XVII. Technical Congress and Exhibition of Turkey Construction Engineering, Istanbul, Turkey (2004).

2. Helsel, D.R. and Hirsch, R.M. "Statistical methods in water resources. Techniques of water-resources investigations of the united states geological survey", Book 4, Hydrologic Analysis and Interpretation, Chapter A3, Amsterdam (1992).

3. Gumus, V., Evaluation of Firat River Basin Streamflow by Trend Analysis, Institute of Science, Department of Civil Engineering, Harran University, Sanliurfa, Turkey (2006).

4. Ceribasi, G., Estimation of Sediment Discharge Transported in Sakarya River by Using Trend Analysis Method, Institute of Science, Department of Construction, Sakarya University, Sakarya, Turkey (2010).

5. Ceribasi, G., Dogan, E. and Sonmez, O. "Evaluation of Sakarya river streamflow and sediment transport with rainfall using trend analysis", Journal of Fresenius Environmental Bulletin, 3A, pp. 846-852 (2013).

6. Ceribasi, G., Dogan, E. and Sonmez, O. "Evaluation of meteorological and hydrological data of Sapanca basin by trend analysis method", Journal of Environmental Protection and Ecology, 2, pp. 705-714 (2014).
7. State Hydraulic Works (DSI), Stream Flow and Sediment Station Data of West Black Sea Basin, East Black Sea Basin and Sakarya Basin (2010).

8. State Meteorological Service (DMI), Rainfall Station Data of West Black Sea Basin, East Black Sea Basin and Sakarya Basin (2013).

9. Ocal, O., Determination of Rainfall - Runoff - Sediment Transport Relationship in Watersheds by Using Artificial Neural Network Algorithm, Institute of Science, Department of Civil Engineering, Pamukkale University, Denizli, Turkey (2007).

10. Partal, T. Estimation of Turkish Precipitation Data Using Artificial Neural Networks and Wavelet Transformation Methods, Institute of Science, Department of Civil Engineering, Istanbul Technical University, Istanbul, Turkey (2007).

11. Sahin, M., Rainfall-Runoff Model Using an Artificial Neural Network Approach for Black Sea Catchments, Institute of Science, Department of Civil Engineering, Istanbul Technical University, Istanbul, Turkey (2007).

12. Oguz, V., Monitoring Suspended Sediment Transport of Korubasi-Arak Stream by Analytical Methods, Institute of Science, Department of Soil Science, Graduate School of Natural and Applied Sciences, Ankara University, Ankara, Turkey (2010).

13. Yildirim, E., Classification of Soil Properties Using Absorptive Characteristics of Seismic Waves, Institute of Science, Department of Civil Engineering, Sakarya University, Sakarya, Turkey (2013).

14. Buyukkaracigan, N. and Kahya, E. "The dependency analysis of annual peak flows of streams in Konya Basin", In: Proc. of the International Conference on Water Problems in the Mediterranean Countries, Ankara, Turkey (1997).

15. Mann, H.B. "Non-parametric tests against trend", The Econometric Society, 3, pp. 245-259 (1945).

16. Kendall, M.G., Rank Correlation Methods, 4th Ed. Charles Griffin, London (1975).

17. Van Belle, G. and Hughes, J.P. "Nonparametric tests for trend in water quality", Water Resources Research, 1, pp. 127-136 (1984).

18. Partal, T. and Kucuk, M. "Long-term trend analysis using discrete wavelet components of annual precipitations measurements in Marmara region (Turkey)", Physics and Chemistry of the Earth, 18, pp. 1189-1200 (2006).

19. Gumus, V. and Yenigun, K. "Evaluation of lower Firat basin streamflow by trend analysis", 7th International Advances in Civil Eng. Conf., YTU, Istanbul, Turkey (2006).

20. Kalayci, S. and Kahya, E. "Assessment of streamflow variability modes in Turkey 1964-1994", Journal of Hydrology, 1-4, pp. 163-177 (2006).

21. Yu, S., Zou, S. and Whittemore, D. "Non-parametric trend analysis of water quality data of rivers in Kansas", Journal of Hydrology, 1, pp. 61-80 (1993). 
22. Cengiz, T., Kahya, E. and Karaca, M. "Trends and annual cycles in Turkish lake levels", In: Proc. of the International Association of Hydraulic Engineering and Research Congress, Thessaloniki, Greece (2003).

23. Aris, P., Sophia, M. and Antonios, P. "Simulation and trend analysis of the water quality monitoring daily data in Nestos river delta", Contribution to the Sustainable Management and Results for the Years 2000-2002, Environ Monit Assess, 3, pp. 543-562 (2006).

24. Hong, W., Leen-Kiat, S., Ashok, S. and Xun-Hong, C. "Trend analysis of streamflow drought events in Nebraska", Water Resources Management, 2, pp. 145164 (2008).

25. Atalay, I., Applied Hydrography-I, Ege University, Faculty of Arts, Izmir, Turkey (1986).

26. Bakir, H. Determination of Erzurum Ilica Sinirbasi Stream Basin Rainfall and Stream Flow Characteristics, Ataturk University, Erzurum, Turkey (2003).

27. Atalay, A. and Ikiel, C. "Trend analysis of monthly and annual flow values of Sakarya river", International Symposium on Geography, Environment and Culture in the Mediterranean Region, Balikesir, Turkey (2007).

28. Ikiel, C. and Kacmaz, M., Global Evolution; Involving Change of Climate. Natural Resources and Human Politics, Italy (2007).

\section{Biographies}

Gokmen Ceribasi is an Assistant Professor in the Department of Technology Faculty at Sakarya University. He graduated with $\mathrm{PhD}$ from the University of Sakarya in 2014. He has published many works in different fields of civil engineering.

Emrah Dogan is an Associate Professor in the Department of Civil Engineering in Sakarya University. He received a BS degree in Civil Engineering in 2001. He graduated with $\mathrm{PhD}$ from the University of Sakarya in 2008. He has published many works in different fields of civil engineering.

Ugur Akkaya is a Lecturer in the Department of Architecture and urban planning in Abant Izzet Baysal University. $\mathrm{He}$ is a $\mathrm{PhD}$ student in Sakarya University. His areas of expertise are flood risk management, hydraulic, fluid mechanics, hydrology and meteorology.

Ugur Erkin Kocamaz is a Lecturer in the Department of Computer Programming at Uludag University. $\mathrm{He}$ is a $\mathrm{PhD}$ student at Sakarya University. His areas of expertise are artificial neural networks and computer and information systems. 